ISSN: 0213-3563

http://dx.doi.org/10.14201/azafea2019213354

\title{
VOCES Y SILENCIOS DE LA TIERRA EN LA COMPOSICIÓN POLIFÓNICA DE LAS GEOGRAFÍAS ÉTICO-POÉTICAS SUR-SUR
}

\author{
Voices and silences of the earth in the polyphonic composition \\ of the south-south ethico-poetic geographies
}

\begin{abstract}
Ana Patricia Noguera ${ }^{1}$; Diana Alexandra Bernal ${ }^{2}$ y Sergio Echeverri ${ }^{3}$ Grupo de Investigación en Pensamiento Ambiental. Departamento de Ciencias Humanas. Universidad Nacional de Colombia. Sede Manizales
\end{abstract}

Recibido: 3 de abril de 2019

Aceptado: 30 de agosto de 2019

\section{RESUMEN}

La composición polifónica musical nos permite hablar de la emergencia, en el sur y desde el sur que somos, de Voces de la Tierra, que han susurrado,

1. Actualmente es profesora titular y emérita del Departamento de Ciencias Humanas de la Facultad de Administración, de la Universidad Nacional de Colombia, Sede Manizales, investigadora del Grupo de Pensamiento de Pensamiento Ambiental de la misma Universidad, desde 1987 y directora desde el año 1996, en cuyo seno ha publicado, como autora y coautora, 32 libros y 107 artículos sobre Pensamiento Ambiental Latinoamericano. Universidad Estadual de Campinas, Brasil; maestría en Filosofía en la Universidad Nacional de Colombia, Sede Bogotá, y licenciatura en Filosofía y Humanidades en la Universidad Santo Tomás de Aquino en Bogotá.

2. Ingeniera Ambiental de la Universidad Nacional de Colombia Sede Palmira, Magíster en Geografía de la Universidad Estadual de Campinas, Actualmente es profesora ocasional de la Universidad Nacional de Colombia, Sede Palmira, y realiza doctorado en Geografía en la Universidad Estadual de Campinas. Es Investigadora del Grupo de Pensamiento Ambiental de la Universidad Nacional de Colombia, Sede Manizales.

3. Diseñador Visual de la Universidad de Caldas, Colombia, Magíster en Estética y Creación, de la Universidad Universidad tecnológica de Pereira, Colombia; Actualmente es Investigador del Grupo de Pensamiento Ambiental de la Universidad Nacional de Colombia, Sede Manizales, profesor invitado Ad Honorem a la cátedra Magistral de Pensamiento Ambiental de la Universidad Nacional de Colombia Sede Manizales, y realiza un doctorado en Diseño y Creación, en la Universidad de Caldas. 

VOCES Y SILENCIOS DE LA TIERRA EN LA COMPOSICIÓN POLIFÓNICA DE LAS GEOGRAFÍAS ÉTICO-POÉTICAS SUR-SUR

cantado, llorado o gritado el dolor producido por las maneras de habitar humanas construidas en la modernidad cosificadora de la Tierra y del mundo de la vida, modernidad mercantil, industrial y global cuya ética se ha reducido a valores absolutamente euro-antropo-racional-centristas, permeados por el valor supremo del capital. Este artículo emerge de pensadores ambientales latinoamericanos y otros que han sospechado radicalmente de la ética ambiental surgida a partir de la conferencia del Club de Roma o del Informe Burndtland. Intentamos desplegar lo ético, como ethos, que en griego significa casa, y desde este lugar de enunciación intentamos salirnos del sujeto y del objeto en la variación ética ambiental eurocentrista. Y proponemos, con las voces de la Tierra Sur, Abya Yala, diseños del ethos ligado óntica-relacionalmente con el cuerpo-tierra. Diseñamos, inspirados en Husserl, Heidegger, Deleuze, Guattari, Ángel-Maya, Enrique Leff, Echeverri, otros y voces de montañas, animales, ríos, y plantas, la vida; territorios de libertad entendida esta como expansión de los cuerpos en la naturaleza y de paz integral y completa. Defendemos que no puede haber paz si no amamos ni respetamos la Tierra que somos. Esto exige el giro óntico-etico-estético-político de la ética en clave de un Pensamiento Ambiental Sur.

Palabras clave: Pensamiento Ambiental Sur, Ética ambiental, Ethos, Geodiseño, Diseño de transición, Ethos-cuerpo-tierra, Geopoéticas, Ser estando, Estar siendo, Comunalidad, Paz Integral.

\section{ABSTRACT}

The polyphonic musical composition allows us to speak of the emergence, in the South and from the south that we are, of Voices of the Earth. These voices have whispered, sung, cried or shouted the pain produced by the ways of inhabiting the world built in the modernity of the earth and the world of life. This commercial, industrial and global modernity has reified the Earth and the world of life. And the modern ethics have been reduced to absolutely Euro-anthropo-rational-centrist values, permeated by the supreme value of capital. This article emerges from Latin American environmental thinkers and thinkers-others who have radically suspected the building of environmental ethics emerging from the conference of the Club of Rome or the Burndtland Report. We try to articulate the adjective ethical, understanding ethos as house in Ancient Greek. Following the voices of the South land, Abya Yala, we try to abandon the idea of subject and the object of the eurocentric environmental ethic, and propose new designs of the ethos, linked ontically-relationally with the body earth. Inspired by Husserl, Heidegger, Deleuze, Guattari, Ángel-Maya, Enrique Leff, Noguera, Echeverri and others, and also by the voices of mountains, animals, rivers, and plants, by the life itself, we try to design territories of freedom. This freedom is 
ANA PATRICIA NOGUERA, DIANA ALEXANDRA BERNAL Y SERGIO ECHEVERRI VOCES Y SILENCIOS DE LA TIERRA EN LA COMPOSICIÓN POLIFÓNICA DE LAS GEOGRAFÍAS ÉTICO-POÉTICAS SUR-SUR

understood as the expansion of the bodies in nature and as a complete peace. There cannot be peace, if we do not love or respect the land that we are. This demands the ethical-ethical-aesthetic-political turn of ethics in the key of a South Environmental Thought.

Key words: South Environmental Thinking, Environmental ethics, Ethos, Geo-design, Transition design, Ethos-body-earth, Geopoetics, Being, Being, Communality, Integral Peace.

\title{
1. LA URGENTE NECESIDAD DE PREGUNTAR POR LO ÉTICO-AMBIENTAL COMO GEO-GRAFÍA ÉTICA-POÉTICA
}

\author{
"Cuanto más originario sea un pensamiento, \\ tanto más rico será lo impensado en él. \\ Lo impensado es el don supremo que un pensamiento ha de conceder". \\ Martin Heidegger. “¿Qué significa Pensar?”.
}

Generalmente cuando nos preguntamos por algo es porque no lo conocemos o porque creemos que hay algo que falta por conocer; algo que puede estar ausente en su explicación. Si nos preguntamos por lo ético-ambiental es porque encontramos que en los discursos políticamente correctos sobre ética ambiental lo ambiental no aparece. O sea: lo ambiental, aquello que no es objeto ni externalidad, aquello que no es recurso, aquello que no se agota en la mera instrumentalidade técnica; lo ambiental como densas, complejas, sorpresivas y enigmáticas relaciones entre las culturas y las organizaciones ecológicas, entre los entramados de vida simbólicos y los entramados de vida bióticos (Noguera, 2000 y 2004), aún no está presente en la ética ambiental predominante. Está presente en pensamentos-otros (Ángel-Maya, 2000, 2000 a, 2001, 2001 a, 2001 b, 2001 c, 2001 d, 2002), emergentes de exterioridades sur, de alteridades radicales (Grosso, 2015). Así, encontramos que cuando se piensa en la ética ambiental convencional, políticamente correcta, inspirada en Kant y en las propuestas éticas de la Filosofía moderna, esta es comprendida desde su aparecer ontológico, como una ética emergente del sujeto, que se expande al objeto para introducirlo en el sistema valorativo universal, unicista, homogéneo, patriarcal, eurocentrista y por tanto sin lugar, sin Tierra, sin mundo de vida, sin cuerpo.

En esta escritura proponemos configurar una senda geo-fenomenológica donde gracias a la Tierra como ethos y lugar de emergencia de todo ethos, 
acontecen des-ocultamientos y ocultamientos del ser del ethos como habitar y del ethos del ser, como hábitat.

Sobre el doble carácter del ser, nos apoyamos en la argumentación teórica expuesta por Heidegger a lo largo de su pensamiento. El doble carácter de ocultamiento-desocultamiento no es un proceso cerrado; es una constante transformación que va variando según las maneras de ocultar y desocultar, de acceder a los entes, de evocar, de nombrar. Varía según las maneras como nos dirigimos a las cosas. La privación del ser como ocultamiento, no debe ser confundida como una negación del ser sino como una manifestación del ser, como aquel acto en el que las cosas se hacen patentes, se traen a presencia en una doble lucha entre Tierra y mundo, siendo el mundo lo que se hace patente como luz, mientras que Tierra, aquello que se retrae en sí, auto-ocultándose. Aquí el ente se ofrece como algo diferente de lo que es, y como algo que también es, siendo este negarse la posibilidad de que el ente pueda ser, o darse.

Cada manera de pensar tiene en sí un camino que permite diversas posibilidades de sentir, pensar y crear mundo, es decir, posibilidades de manifestar el ser. De este modo, si una forma de pensar se impone sobre otra u otras, esta termina ocultando otras maneras de ser pues, enceguecida por sí misma, no puede ver que ella es sólo uno de tantos sentidos; así se instituye como algo totalitario y dominante.

En estos tiempos de despliegue pretendidamente universal de la razón moderna, nuestras maneras de habitar, es decir, nuestro ethos sigue apresado por la ciencia moderna positivista y la razón instrumental, donde el hábitat se somete al cálculo, la cosificación y la mercantilización del mundo de la vida. Olvidamos que las ciencias solamente son maneras de expresión del ser-ahí, Dasein (Heidegger, 2012).

Así, en el habitar contemporáneo como una continuación del proyecto de la modernidad, la vida se asume en la levedad del ser (Tuan, 2013). La pérdida del otro-lo otro es una suerte de negación que conduce a perder posibilidades de manifestaciones-otras del ser. La razón presente en la ciencia es una manera de dejar ver algo, pero no la manera de dejar ver; ella es logos, es discurso que hace tornar manifiesto aquello de lo que se habla como un hacer-ver algo en su ser junto con algo; hacer ver algo como algo (Heidegger, 2012, 114-115). Debido a esto la ciencia se erige más como una ocultación que como una desocultación.

En esta época, el saber dominante es la ciencia fáctica, con su supuesto de perfección y avance ilimitado que se convierte en práxis ideal; práxis de perfeccionamiento y de la necesidad de exactitud como método de validez. Una 
ANA PATRICIA NOGUERA, DIANA ALEXANDRA BERNAL Y SERGIO ECHEVERRI VOCES Y SILENCIOS DE LA TIERRA EN LA COMPOSICIÓN POLIFÓNICA DE LAS GEOGRAFÍAS ÉTICO-POÉTICAS SUR-SUR

ciencia que abandona la intuición y la intencionalidad, y que bajo la idea de libertad, control y razón opta por creer en la neutralidad y distanciamiento del mundo, tal y como lo expresa el padre de la fenomenología, Edmund Husserl en su libro la Crisis de las ciencias y la fenomenología trascendental (Husserl, 1991). Esta ciencia se asume metafísica y al distanciarse del mundo niega aquello sobre lo cual se fundan todos los saberes, desembocando en una incapacidad del ser humano para responder por el sentido de su propia existencia. En ella el discurso empírico encubre la experiencia y la transforma en mera evidencia de constataciones objetivas -recordando que lo objetivo nunca es experienciable en sí mismo.

\section{La uRgencia de una Geo-etica. La CRISIS de SENTIDo de las Ciencias EUROPEAS EN LA CRISIS AMBIENTAL PLANETARIA}

Leonardo Boff, pensador ambiental brasileño, abre para nosotros la posibilidad de pensar la ética ligada a la Tierra, como una geo-ética, en el sentido de un geo-ethos:

El término «ética» viene del griego ethos. [...] Ethos, con «e» larga, significa la morada, el abrigo permanente tanto de animales (establo), como de seres humanos (casa). En el ámbito de la totalidad de la madre naturaleza (llamada physis filosóficamente y «Gaia» míticamente), el ser humano delimita una parcela y se construye en ella una morada. [...] Esta es la obra de la cultura. [...]

El centro del ethos (morada) es el bien (Platón), pues sólo él permite que alcancemos nuestro fin, que consiste en sentirnos bien en casa. [...] Para Aristóteles, el centro del ethos (la moral) es la felicidad, no en el sentido subjetivista moderno, sino en sentido objetivo, como situación de autonomía vivida en el nivel personal y social (polis). [...]

Ethos escrito con «e» breve del alfabeto griego designa las costumbres, esto es, el conjunto de valores y de hábitos consagrados por la tradición cultural de un pueblo. Ethos como conjunto de los medios ordenados a un fin (el bien/la autorrealización) se traduce en el espacio cultural latino y moderno por «moral» $[\ldots]$

[...] De aquí se desprende que el «ethos/moral» siempre va en plural, mientras que el «ethos/casa» siempre en singular.» (Boff, 2001, 26-27).

Esta proximidad de la ética ambiental con el geo-ethos, es decir, con un habitar la casa a partir del bien vivir, abre a su vez la posibilidad de establecer un diálogo con Abya Yala: Tierra Fértil, Tierra Madura, Tierra Generosa, Tierra en Florecimiento y Buen Vivir. Este nombre-acontecimiento, dado 

DE LAS GEOGRAFÍAS ÉTICO-POÉTICAS SUR-SUR

por la cultura Cuna al continente que España denominó América, sigue significando para las culturas cunas que lograron sobrevivir a los procesos de colonización y esclavitud que duraron cuatrocientos años, una alternativa geo-poética-ética-política de diseño para la transición civilizatoria y el cambio cultural ante la crisis civilizatoria, de humanidad, planetaria y por lo tanto ambiental que estamos viviendo.

América Latina ha retornado a pensarse-Sur. Este pensarse-Sur, tiene varias maneras de comprenderse: Pensar-Sur, Pensarnos como Sur, desde el Sur y hacia un Sur-Sur. El sur ha devenido en geografía poético-política, potenciadora de remembranzas, evocaciones, olvidos, huellas, presencias y ausencias que han sido fundamentales en el Pensamiento Ambiental Sur, especialmente, en la re-construcción, re-configuración de nuestro ethos ambiental.

Sin embargo, este Sur venía emergiendo en el pensamiento Sur, como metáfora geopoética, de una Europa, que ante el dominio de un pensamiento único, universal, hegemónico y eurocentrista, iniciaba su propio devenirotra.

En 1935, Edmundo Husserl daba una conferencia en Viena, que llamó "La Crisis de la Filosofía de la Humanidad Europea" (Husserl ,1962), donde anunciaba cómo la crisis de las ciencias europeas, no era una crisis de método, como 300 años atrás afirmara Descartes, sino una crisis de sentido. La palabra sentido, significaba dirección: Husserl planteaba en esa conferencia cómo las ciencias habían perdido su norte porque se habían alejado de la filosofía y la filosofía se había alejado de la autorreflexión, función primordial, decía Husserl, de la filosofía misma. Pensar el pensar era tarea fundacional de la filosofía, pero ella, se había reducido a epistemología, que a su vez se había convertido en meretriz de la ciencia positiva. La crisis se manifestaba como desencantamiento y desgarramiento del mundo de la vida y era la guerra su mayor expresión. Husserl hablaba desde Europa, trágico lugar donde habían sido posibles acontecimientos tan contradictorios como la poesía de Schiller, la música de Beethoven y la I Guerra Mundial. Sin embargo, cuando Husserl hablaba de perder su norte, estaba confirmando que el Sur no pertenecía a la filosofía europea, si estaba dentro del círculo de la autorreflexión, lo cual en perspectiva del ethos ambiental, acentuó que desde el Sur tendrían que emerger maneras otras de pensar, lo que realmente, ya estaba sucediendo en el Sur-Sur. Si el norte era el punto cardinal más importante para Europa, el sur tendría que serlo para América-Abya Yala, como lo desplegaría el Pensamiento Ambiental Sur emergente de Rodolfo Kusch (1976), Augusto 
ANA PATRICIA NOGUERA, DIANA ALEXANDRA BERNAL Y SERGIO ECHEVERRI VOCES Y SILENCIOS DE LA TIERRA EN LA COMPOSICIÓN POLIFÓNICA DE LAS GEOGRAFÍAS ÉTICO-POÉTICAS SUR-SUR

Ángel-Maya (1996), Enrique Leff (2001), Jaime Pineda (2016) y Patricia Noguera $(2004,2012,2016)$, entre otros pensadores ambientales latinoamericanos.

Por la soledad profunda desde la cual hablaba Husserl en la Viena de 1935, por la música silenciosa que emanaba de la palabra husserliana en esa conferencia, intuimos que la crisis también emergía de la ausencia de un geo-ethos, es decir, de lugar. ¿Dónde estaba el mundo de la vida, si en ese momento la universalización de las verdades positivistas subsumía toda posibilidad de diferencia, por medio de la guerra? La crítica que Husserl hacía al reduccionismo positivista, sobre todo en la Crisis de las Ciencias Europeas y la Fenomenología Trascendental, libro que recogió y expandió la inolvidable conferencia de Viena, abría la fenomenología a lo estético, y la ética a la estética, porque la palabra "sentido" permitía una gran variedad de contactos con y en el mundo de la vida que, para el Husserl de 1935, era el horizonte de la conciencia intencional, como intersubjetividad trascendental, solo... y acá está lo más importante, en el mundo de la vida como co-relato.

En Fenomenología de la conciencia del tiempo inmanente (1959), Husserl encuentra un lugar trágico en sentido nietzscheano: la música deviene en un tiempo que es a la vez eterno y fugaz expresa una hermosa, maravillosa y potente manera de disolver la tensión, entre lo finito y lo infinito. En la música se realizan tensiones inexplicables entre tiempos y espacios; ella es tensión espaciotemporal. Es atmosférica, es geopoética (Pardo, 1991). Sin pretensiones lógicas, ella expresa distintas variedades de disolución del tiempo en geografías y de estas en devenires. Sin comprometerse con el tiempo de los relojes, el tiempo se torna eternidad y el espacio geografía poética del mundo de la vida. El cuerpo, como corporeidad, como sensualia, como contacto, se hace lugar en esa tensión, donde la separación permite la conexión; donde el cuerpo solo es cuerpo en cuanto mundo de la vida y el mundo de la vida solo es posible como cuerpo (Noguera, 2004), constituyéndose los dos por una especie de dualética, según diría más tarde Andrés Ortiz-Osés (1994), que permite comprender el cuerpo como lo in-corpóreo en un bucle donde la in-corporación no es otra cosa que ese momento fenomenológico donde el mundo de la vida es cuerpo en expansión y el cuerpo es mundo de la vida, también en expansión.

Pero el cuerpo, como lugar de lo sentido, como sensualia, estaba invisibilizado por el positivismo, desde el siglo XVII. La razón instrumental ocupaba el lugar de la razón como autorreflexión. La razón instrumental, es decir, la razón que explica, universaliza y legisla sobre el mundo de la vida, predominaba como única luz que develaba la Verdad. El éxito de las ciencias 
ANA PATRICIA NOGUERA, DIANA ALEXANDRA BERNAL Y SERGIO ECHEVERRI VOCES Y SILENCIOS DE LA TIERRA EN LA COMPOSICIÓN POLIFÓNICA DE LAS GEOGRAFÍAS ÉTICO-POÉTICAS SUR-SUR

del cálculo y la positivización del mundo de la vida era arrollador y arrogante. Configuraba, por sus efectos, el paradigma científico-técnico en el que el mundo moderno se estableció y se convirtió en su único sentido y telos: el Desarrollo. Posible solamente bajo el imperio del positivismo universal, el desarrollo, hermano gemelo del capitalismo y de la guerra moderna, ha reducido el mundo de la vida a objeto, y ha subsumido el horizonte de la conciencia intencional fenomenológica a mundo calculado.

Con su imagen de la crisis, Husserl abrió para nuestro pensamiento Ambiental una fisura marginal a los discursos sobre medio ambiente que nacieran treinta y tres años después, en la primera conferencia mundial del Club de Roma. Esta fisura permitió re-conocer la insuficiencia de la ciencia moderna, anclada en la relación sujeto-objeto, para responder a las urgencias propias de un siglo donde la guerra, mundializada gracias a las máquinas de poder, sería la manera de mostrar las posibilidades de una racionalidad universal que por supuesto estaría por fuera de toda diferencia y diversidad.

Cuando Husserl describe la crisis de las ciencias modernas, no por su eficacia, sino por la gran ausencia de sentidos, está colocando la crisis en el corazón de la cultura, y está dándole a la crisis un carácter estético en sentido expandido. Esto significa que la crisis de la ciencia moderna expresa una crisis de la cultura y por tanto de aquello que constituye cultura: sus redes simbólicas, es decir, sus maneras de conocer, sus saberes, sus creencias, sus lenguajes, sus maneras de crear, sus relaciones con otras culturas, es decir, su ethos.

Desde el Romanticismo, se pre-sentía la emergencia de esta crisis cultural. Los artistas románticos habían mostrado ya en sus obras de arte la tragedia de nuestro habitar tiránico moderno. Los escritores, poetas, músicos, pintores, arquitectos y pensadores del Romanticismo europeo habían ya mostrado su inquietud frente a la desolación de la naturaleza, del paisaje y del hombre, abandonado de los dioses, desacralizado, reducido al cálculo, a la estadística y a la medición.

Sin embargo, la crisis ambiental se evidencia como discurso el 15, 16 y 17 de junio de 1968, cuando se realiza la primera conferencia mundial del Club de Roma, conferencia en la cual se hizo énfasis en el futuro de la humanidad, se propuso colocar a la humanidad como prioridad en el desarrollo científico y tecnológico del mundo y hacer todos los esfuerzos educativos para que todas las actividades humanas se enfocaran a privilegiar el bien de la humanidad sobre cualquier otro valor. Hasta ahí no había nada nuevo ni distinto a los ideales de la modernidad. Las tareas propuestas en esta primera 
ANA PATRICIA NOGUERA, DIANA ALEXANDRA BERNAL Y SERGIO ECHEVERRI VOCES Y SILENCIOS DE LA TIERRA EN LA COMPOSICIÓN POLIFÓNICA DE LAS GEOGRAFÍAS ÉTICO-POÉTICAS SUR-SUR

conferencia consagraban de nuevo al Hombre y a la Humanidad (europeos), como centros y metas finales de la ciencia, la tecnología y el desarrollo; sin embargo, algo nuevo emergía en los discursos académicos del Club de Roma: que el bienestar humano del que estaban disfrutando las clases altas y medias norteamericanas y europeas era una ilusión si se continuaba con un desarrollo sin límites de una sociedad, la norteamericana y europea, que estaba creciendo económica, tecnológica e industrialmente sin tener en cuenta los límites de los ecosistemas, de las culturas, de la vida misma. La crisis de la filosofía y de las ciencias europeas se expresaba ahora en términos de crisis ambiental, que era esencialmente una crisis originada por la pretensión de la ciencia, de des-ocultar el ser, ocultado por la ausencia de sentido, de una ciencia instituida e instituyente de la Razón Universal.

El Pensamiento Ambiental Sur, emerge como un preguntar pensante (Heidegger, 2005), esto es: como posibilidad y no como una verdad científica que se erige sobre sí misma como algo incondicional. Para este preguntar pensante recurrimos al mostrar-se en sí de la fenomenología, y como modo de acceso a este mostrar-se, nos guiamos por la espacialidad del ser, es decir, por el estar como manera de ser del ser, evocando la pregunta ¿habita poéticamente el hombre? Porque es en el habitar-hábitat que se despliega el ser como estando; y a ese contacto indefinible, inexpresable matemáticamente, inapresable geométricamente, decible solo en el silencio poético del ser estando, lo estamos llamando ethos. La relación, inmanente desde el punto de vista óntico y transcendente desde el punto de vista ético-estético, afecta, con-mueve, trans-forma, de-forma, con-forma y re-forma, tanto al habitar como al hábitat.

La pregunta por el habitar humano será, en este sentido, la pregunta ética -ambiental. No sólo ética-ecológica, sino ética-ambiental en tanto lo ambiental es una emergencia compleja relacional entre el hábitat, organizaciones eco -espaciales, y el habitar en sus modos y maneras de construir-se. El afuera, el otro, lo otro, la intemperie, la exterioridad radical, permiten, como hábitat, la emergencia de geo-eco-bio-socio-poéticas. Así el pensar está coligado con el habitar y los dos, con el construir (Heidegger, 2012 a). La cercanía óntica entre los verbos habitar y morar es cercanía entre vecindad y moralidad. El ethos comporta alteridad. Com-portar, significa llevar consigo; el ethos lleva consigo el habitar y el hábitat, dupla característica del ser estando y del estar siendo. Así, el habitar como realización del ser estando se realiza en el hábitat como lugar, hogar, casa, donde es posible y se hace posible dicha realización, en un des-ocultamiento que en sí mismo, es ocultamiento. El cuidado 
ANA PATRICIA NOGUERA, DIANA ALEXANDRA BERNAL Y SERGIO ECHEVERRI VOCES Y SILENCIOS DE LA TIERRA EN LA COMPOSICIÓN POLIFÓNICA DE LAS GEOGRAFÍAS ÉTICO-POÉTICAS SUR-SUR

de sí es aquí la única manera de des-ocultamiento de lo ocultado. Cuidar es dejar que el ser se muestre, se exprese poéticamente. Cuidar es nombrar los modos del ser para que este se exprese. Y como nombrar estos modos del ser solo es posible en el lenguaje, entonces, el lenguaje, al nombrar, permite que el ser sea y que el ser del ser sea aquello que habita y que lo habita: el lenguaje.

Emergen de estas polirrítmicas y singulares maneras de nombrar, polifonías críticas del Pensamento Ambiental Sur, y por supuesto, de la filosofía, no como disciplina sino como pensar el pensar.

\section{Polifonías geo-Ético-estéticas sur}

Voces de tesituras, texturas, tonos, colores y gamas diversas, componen un coro que canta las geografías poéticas Sur. Ninguna voz sobresale. Ninguna busca cantar mejor que la otra. Ninguna reclama derechos de autor; ninguna se impone para dominar las otras. Ninguna se vende ni se compra, ninguna se exhibe para opacar a las otras. Las voces de la Tierra, acuosas, montañosas, pétreas, espesas, salvajes, meditativas, telúricas, sinuosas, cálidas, heladas, aéreas, reptantes, agudas, graves, profundas, celestiales, enraizadas, volátiles, marinas, ribereñas, cariñosas, amantes, filiales, fraternales, uterinas, maternales, paternales, amorosas, lacrimosas, cansadas, nacientes, agonísticas, murientes, nutricias, nutrientes... las voces de la Tierra aún no han sido escuchadas en su alteridad radical por la ética ambiental.

Anclada aún en la tarea de pensar lo ético y el ethos desde el humano, en lo humano y para lo humano, la ética ambiental sigue apresada en principios, valores y metas universales que emergerían como una creación humana, para dirigirse a la Tierra, la naturaleza y el planeta, como si la humanidad estuviese por fuera de ellas y de él. O dicho de otra manera, como si el sujeto que piensa la ética ambiental, la pensara desde un mundo meta-físico, para cuidar una Tierra, una naturaleza y un planeta que le pertenecen a ese sujeto trascendental. Así, desde la razón universal, esencia del sujeto transcendental, se podrían deducir principios, valores y metas universales, que compondrían el cuerpo teórico de la ética ambiental.

Deambulan todavía en los pasillos del ambientalismo académico la preocupación no por el cuidado de la Tierra en cuanto Tierra, sino la preocupación por la Tierra en tanto fuente de recursos para la humanidad occidental moderna, compuesta por una intersubjetividad trascendental (Husserl, 1982), que 
ANA PATRICIA NOGUERA, DIANA ALEXANDRA BERNAL Y SERGIO ECHEVERRI VOCES Y SILENCIOS DE LA TIERRA EN LA COMPOSICIÓN POLIFÓNICA DE LAS GEOGRAFÍAS ÉTICO-POÉTICAS SUR-SUR

es el nombre que la fenomenología husserliana le dio al sujeto trascendental kantiano (Kant, 1972) dialogante. La ética ambiental aún está comprometida con aquella hermosa y no menos problemática construcción kantiana: la ley moral como un imperativo categórico, es decir: la ley moral como universal y el imperativo como emergente de las categorías del entendimiento que en la Crítica del Juicio constituyen el sujeto moral como razón moral trascendental.

Esta dependencia ontológica, epistemológica, ética, estética y política, que América Latina ha tenido del sistema-mundo-occidental-moderno, ha ocultado el ethos-Sur, que se des-oculta en tanto el pensamiento ambiental se aleja del predominio epistemológico del sujeto-objeto, y se acerca hasta disolverse en el ethos presente en los tejidos, entramados, configuraciones, metamorfosis del habitar-hábitat.

Caminos ocultados por la metodología o camino del logos y de la lógica, van emergiendo serena y cuidadosamente, para pensar en clave de un ethosSur. Ecosistema-cultura (Ángel-Maya, 1996), cuerpo-mundo-de-la-vidasimbólico-biótico (Noguera, 2004), superficies del contacto (Mesa, 2010) cuerpo-tierra (Noguera, 2012), ethos-cuerpo (Chacón, 2012), habitar-habitat y ethos-cuerpo-tierra (Noguera y Echeverri, 2019), han configurado una constelación de relaciones humano-tierra, donde lo humano se ha disuelto poéticamente en la tierra fértil, madre, casa y creadora; en el todo de la naturaleza, como lo anhelaba Friederich Hölderlin (Hölderlin, 2007), en las postrimerías del siglo XVIII. Estos caminos recogidos cuidadosamente en las metodoestesis (Noguera, 2019)4: los caminos del sentir, emergen y entran en conversación con las metodologías - sin subsumirlas ni ser subsumidas por éstas-, para darle a la ética ambiental, un giro profundo, como la Tierraethos que la soporta. El mundo de la vida como obra de arte, cuidadosamente configurado por la vida misma como Tierra, debe ser en tiempos de penuria y escasez de alteridad, la fuga armoniosa y trágica, a la manera de Bach

4. Imagen conceptual en construcción por parte de Ana Patricia Noguera, que ha permitido nombrar los caminos del sentir, lo sentido, los sentidos, la sensibilidad, lo sensible. Estos caminos ya los habíamos desplegado en nuestro pensamiento ambiental Sur, pero ante la urgencia de salir del paradigma cientificista, Noguera (2019) decidió nombrar como Metodoestesis. Así, conversar con las metodologías, propias de la modernidad, que desde la conferencia de Viena, Husserl cuestionó radicalmente, y que aún dominan las investigaciones en Ciencias Sociales cuya preocupación ética sigue anclada en los aprioris morales kantianos y postkantianos, podría configurar una fisura, un umbral, en el que ya no existiera una interioridad opuesta a una exterioridad, sino un entramado de conexiones, un flujo geo-fenomenológico que permitiera pensar en un Ethos Ambiental Sur. 
y Nietzsche, de esta cultura ingrata y sin paz que ha creído saber la hora (Hölderlin, 2014).

Mientras la ética ambiental post-kantiana continúe deambulando en el mundo de la modernidad aportando incluso nuevas subjetividades y objetividades, nuevos campos de investigación sujeto-objeto, continuará escindida de la Tierra, de los entramados y texturas vivientes. Emergentes en la época de la Ilustración, las Ciencias Sociales -cuyo objeto es el mismo sujeto, trascendental en sus formas de subjetivación, esencial en la razón, y en la reducción científico-técnica del mundo de la vida-, han sido el soporte de una verdad que ha velado la posibilidad de preguntarse por su pertinencia ética y sus sentidos en los mundos de vidas pluriversas.

El giro radical que las voces geográficas Sur le proponen a la ética ambiental incluye la creación de otras partituras, que coloquen en pausa las voces del Sujeto y del Objeto, de los discursos categoriales y universalistas de Hombre, Bien, Mal, Humanidad, Humanismo, Sociedad, Desarrollo, Globalidad, Mundo, Naturaleza, Tierra, Vida, Verdad, Belleza, Justicia, Derecho, Libertad... que han escindido lo humano de la Tierra a partir de una guerra sin precedentes, aún hoy, silenciada por las voces del sujeto dominante.

Las geo-polifonías corales que nuestro Pensamiento Ambiental Sur interpreta y escucha permiten que las monofonías del pensamiento eurocentrista sean escuchadas desde el afuera de los dominios de las Ciencias Sociales y la ética ambiental moderna; el afuera como lugar radical, intemperie donde no existen muros, ni techos, ni suelos, ni puertas ni ventanas. Desde ese afuera habitado por alteridades radicales, las geo-polifonías corales movilizan, desestabilizan y des-sedimentan los cimientos epistemológicos sujeto - objeto, introduciendo la Tierra madre, como oikos, ethos y esthesis en los estudios éticos, sociales, humanos y culturales de la América - Abya Yala que somos.

En las polifonías de la atrocidad están los Gritos de la Tierra como los paisajes de la devastación (Pineda, 2016) que somos en Hidroituango ${ }^{5}$, gritos desolados de corazones atravesados por la atrocidad en Ayotzinapa ${ }^{6}$, llanto doloroso de las madres de Soacha ${ }^{7}$; susurros muchas veces silenciados, de

5. Hidroeléctrica construida por la multinacional EPM que ha devastado el río Cauca y con él, la diversidad ecosistémica y cultural de los Andes colombianos.

6. Masacre de 43 estudiantes normalistas en Iguala, México, entre el 26 - 27 de septiembre de 2014.

7. Madres de jóvenes asesinados por el ejército colombiano para generar miedo en los colombianos y mostrar resultados en términos numéricos de "bajas" de jóvenes de la guerrilla, realizadas por el ejército, durante el segundo mandato del presidente Álvaro 
ANA PATRICIA NOGUERA, DIANA ALEXANDRA BERNAL Y SERGIO ECHEVERRI VOCES Y SILENCIOS DE LA TIERRA EN LA COMPOSICIÓN POLIFÓNICA DE LAS GEOGRAFÍAS ÉTICO-POÉTICAS SUR-SUR

madres, padres, hijos, hijas, hermanos, hermanas, amigos de aquellos que han sufrido juvenicidios, feminicidios, homicidios, eco-cidios y geo-cidios de las guerras que se narran en los trabajos de investigadores colombianos en Ciencias Sociales como Germán Muñoz (2015) o Jaime Pineda (2017); de las madres, padres, hermanos, amigos y amantes de los NN que emergen silenciados y por pedacitos del lecho del Río Cauca que canta un Requiem, documental bella y dolorosamente compuesto por Juan Manuel Echavarría (2013) o el tablero de una escuela en Bojayá (Chocó-Colombia) que expresa la devastación y la desolación que ha dejado en Colombia la guerra que no hemos visto (Echavarria, 2009)

Pero también están presentes, aún veladas por el antropocentrismo, otras voces emergentes de las densas texturas del coro de la vida. Las voces arbóreas, acuosas, pétreas, animales, vegetales, raizales, originarias, nevadas y termales de la vida. Ellas poco a poco, lentamente, dentro de los tiemposgeográficos-otros, telúricos y densos de una naturaleza incognoscible han comenzado a cantar sus pluriversos, gritando su permanente dolor ante la herida profunda que el Desarrollo -hermano del Capitalismo- produce en sus entrañas, en sus pieles, en sus cuerpos. Y son los poetas quienes comprenden las voces de la tierra herida. Son sus poemas los que tallan la tierra; son los cuerpos-tierra danzantes campesinos los que labran la ethos-tierra-madre para el florecimiento de la vida, Abya Yala. Son las guitarras, las flautas, las zampoñas, los tambores, los sintetizadores y una gran diversidad de instrumentos musicales quienes alegran las montañas, remontando las melodías sencillas de la tierra, por los vientos del Sur, para que, desde Alaska hasta la Patagonia, el sur emerja potente, en la única, profunda y bella democracia: las polifonías de la vida.

El giro ético-estético-ambiental de ética ambiental en América Latina urge construir metodoestéticamente el tránsito de un pensamiento ético escindido de la physis, a un geo-pensamiento emergente de los cuerpos - tierra que también somos; en esto consiste la pausa del sujeto y del objeto; de esta pausa, de este silencio epistémico-ético-estético-político, emerge el Pensamiento Ambiental Sur que ya no pregunta ¿cómo conocemos?, sino ¿cómo podemos habitar poéticamente esta hermosa y floreciente tierra?

Uribe Vélez (Colombia, 2006-2010). Los periodistas, cronistas e historiadores críticos de estas masacres llamaron a este fenómeno "falsos positivos". Estas masacres se expandieron al mundo de la academia, de los líderes sociales, de comunidades originarias y ambientales. 
El poeta Nietzsche (Nietzsche, 2000), filósofo del desencantamiento del mundo, profeta de la crisis civilizatoria originada por la escisión entre hombre, cultura y naturaleza, profetizó el dominio del sujeto congnoscente sobre el mundo, la reducción del mundo a objeto conocido gracias a la lógica matemática de la razón calculante, y por tanto, la crisis de esta aventura civilizatoria obnubilada por el kikirikeo de la razón. Esta profecía se ha ido cumpliendo cada vez más profunda, atroz y dolorosamente. La reducción positivista del mundo a mero objeto creó la ilusión de un dominio absoluto sobre las fuerzas de la naturaleza. Esto originó la faústica creencia en un sujeto capaz de develar todos los secretos de la naturaleza, dominar los universos macro y micro, y llegar a ser, por fin, dueño y señor de la naturaleza; vana ilusión de la desmesura humano-euro-centrista.

La crisis de las Ciencias Sociales y humanas hoy tiene que ver con una crisis de sentido (Husserl, 1991), pero también del sentir, de los sentidos, de lo sensible, de las sensibilidades, de la vida sensible (Coccia, 2011) de las otras vidas, encarnadas en poéticas-otras de coexistencia con alteridades radicales, de sentidos-otros, exteriores al sentido occidental-moderno-centrista de habitar la tierra como sujetos, objetivándola a través de la productividad técnica y de la industrialización de su intimidad enigmática.

La crisis ambiental, expresión radical de la crisis civilizatoria, en tanto aquella es crisis de la vida en su totalidad incalculable e inexplicable, tejido que ha permitido incluso el vuelo civilizatorio y la crisis que este vuelo ha gestado, se ha convertido en potencia de un pensar-otro, de un pensar exterior al sujeto, exterior a la disposición del mundo como objeto, a la categorización universal de la singularidad de los contecimientos, exterior al tiempo metafísico e incluso al espacio homogéneo de una globalidad ontológica.

\section{De voces escindidas de la Physis ... a voces emergentes de la Pacha-Mama}

El Pensamiento Ambiental Sur se ha configurado como campo donde convergen maneras de pensar y voces-otras, emergentes de la relación fundacional humano-naturaleza. Las Geografías Sur se despliegan en lugares y maneras de habitar que se distancian de las lógicas del habitar occidental moderno.

Las voces del Pensamiento Ambiental Sur ponen en cuestión, sospecha y crisis los monofónicos conceptos de ambiente propuestos por Naciones 
ANA PATRICIA NOGUERA, DIANA ALEXANDRA BERNAL Y SERGIO ECHEVERRI VOCES Y SILENCIOS DE LA TIERRA EN LA COMPOSICIÓN POLIFÓNICA

DE LAS GEOGRAFÍAS ÉTICO-POÉTICAS SUR-SUR

Unidas, y las Políticas Mundiales sobre Medio Ambiente; estos conceptos han reducido el ambiente a recursos naturales, a objetos de investigación, cuantificación y mercantilización, produciendo así imaginarios y prácticas sociales que reducen la naturaleza a objeto-mercancía que debe cuidarse exclusivamente para que las generaciones futuras de humanos, reducidos a "sujetos", tengan la misma calidad de vida que las generaciones presentes. (Nuestro Futuro Común, 1992). El Pensamiento Ambiental Sur ha tomado la decisión de apartarse de esta concepción antropocentrista de lo ambiental, asumiendo la urgencia filosófica y comunal de volver a pensar lo ambiental no como "recursos" naturales, sino como densas y profundas relaciones entre la naturaleza y aquello singular que emerge de ella con lo humano: la cultura (Ángel-Maya, 1996).

Pensar así lo ambiental exige salirse del circuito epistemológico sujetoobjeto presente en los discursos medio-ambientales políticamente correctos, subsumidos por los discursos del Desarrollo con todos sus prefijos y adjetivos. Pensar lo ambiental así es asumir un pensamiento en resistencia que no responde a las políticas ambientales, donde las sensibilidades, sentimientos, cuerpos, corporalidades e intercorporalidades no son tomados en cuenta en la configuración de los saberes reglados de la educación que se imparte en las escuelas.

La reducción tecno-económica y socio-política del ambiente a objetomercancía excluye naturalezas-otras enigmáticas y profundas, no reducibles a las lógicas humanas occidentales-moderno-centristas, configurando un problema ético, pero no solo ético, sino crucial, hoy: sin los entramados de vida, sin la tierra-madre sería imposible la existencia de los humanos. Entonces ¿por qué la ética ambiental aún es la ética entre sujetos sobre la tierraobjeto?

\section{Giros Ético-Ambientales emergentes del Sur}

Urge, entonces, un giro de ética, que exige la renuncia geo-filosófica al sujeto y al objeto, por cuanto sus relaciones epistemológicas, ontológicas, éticas, estéticas y políticas han configurado la ilusión de universalidad del conocimiento científico y de los conceptos de tierra, vida, naturaleza, sociedad, cultura y humanidad. Urge un giro telúrico, donde la Tierra se considere no solo como escenario y testigo de la guerra de todos contra todos y contra todo (Serres, 1991), sino como madre, como útero que 
ANA PATRICIA NOGUERA, DIANA ALEXANDRA BERNAL Y SERGIO ECHEVERRI VOCES Y SILENCIOS DE LA TIERRA EN LA COMPOSICIÓN POLIFÓNICA DE LAS GEOGRAFÍAS ÉTICO-POÉTICAS SUR-SUR

alberga la vida, el tejido de la vida configurado por hilos maravillosamente únicos, múltiples y diversos, uno de los cuales somos los humanos (Capra, 1998). Es el giro ambiental Sur. No sabemos si las ciencias están decididas a dar ese giro. Esto implica una movilización radical de sus bases epistemológicas; implica un deponer la idea de verdad en sentido objetivo o intersubjetivo por la imagen de pertinencia, saber responsable con la vida, saberes en la multiplicidad y la singularidad que somos (Yáñez, 2010); maneras - otras de pensar-nos, pasar de un pensar lógico lineal, reduccionista a un sentipensar con la Tierra (Escobar, 2014), en todas las direcciones y sin jerarquizar ningún sentido ni dirección. Se trata de incluir la Tierra, la naturaleza, los entramados de vida en el pensamiento sobre lo humano y sus diversas maneras de estar. Se trata de hacer el tránsito del cómo conocemos, al cómo habitamos esta tierra; se trata de trasformar-configurar las palabras que nombran la vida en todas sus creaciones; abandonar los imaginarios sociales que han construido los discursos del Desarrollo, para construir colectiva, lenta y cuidadosamente nuevos imaginarios que potencien las comunidades del Buen Vivir, del Florecimiento de la Tierra: Abya Yala (Noguera, 2016)

Es en el tránsito a un geopensamiento, a una geofilosofía (DeleuzeGuattari, 1993), a una geocultura (Kusch, 1976) de las comunidades ecológicas alternativas (Noguera, 2012) que las ciencias, la técnica, la política y la cultura deben realizar; es en el giro ético ambiental sur, que la investigación social y humana en el siglo XXI deberá colocar todas sus fuerzas; sólo así podremos tener una segunda oportunidad sobre la Tierra.

Sin embargo, las políticas educativas en Colombia están permeadas por una visión antropo-economo-centrista y por supuesto la educación ambiental no incluye a los cuerpos-entre-cuerpos (Nancy, 2003) humanos en el devenir de la Tierra, ni en el tejido profundo de las tramas de la vida. Igualmente, la preocupación de la educación por lo humano no está cruzada por un retorno a la Tierra-madre, ni por una educación en la recuperación y resignificación de la Tierra que somos, sino en educar para continuar con el desarrollo del sujeto, que es el desarrollo del mundo-objeto, y que exige, por tanto, avasallamiento desolador de la Tierra, donde los humanos también somos avasallados y desolados, dado que estamos hechos del lugar que habitamos: la Tierra.

La educación como institución política de los estados-nación modernos, quiebra la sensibilidad de los niños, niñas y jóvenes al reducir la vida a objeto de investigación para poderla dominar, creando imaginarios de desprecio 
ANA PATRICIA NOGUERA, DIANA ALEXANDRA BERNAL Y SERGIO ECHEVERRI VOCES Y SILENCIOS DE LA TIERRA EN LA COMPOSICIÓN POLIFÓNICA DE LAS GEOGRAFÍAS ÉTICO-POÉTICAS SUR-SUR

por la tierra natal, la tierra-madre y nutricia. La educación va inculcando una avidez mortal por el valor económico de la naturaleza dentro del mundo de la producción industrial; esta reducción hace frágiles a los niños, niñas y jóvenes, ante las promesas del desarrollo que traen consigo la ilusión de un vivir mejor.

Si la Educación en América Latina sigue siendo el lugar privilegiado para continuar el proceso civilizatorio, colonizador y neocolonizador, que comenzó Europa hace más de quinientos años en esta América-Abya Yala, tenemos que volver a pensar lo que somos y tal vez olvidar lo que nos han impuesto que debemos ser. Atrevernos a volver a pensar no solo lo ya pensado, sino aquello que no nos habíamos atrevido a pensar, es un acontecimiento de jovialidad: serenidad para pensar tiempos impensables, tiempos enigmáticos, con la alegría que comporta el asombro ante lo desconocido.

En este sentido, hay esperanza: no en las políticas sino en la potencia política de las poéticas del habitar-Sur, manera de habitar desconocida e inexplicable desde las lógicas occidental-Norte-centristas.

\section{ECO-ETHO-DISEÑOS DE TRANSICIÓN A LA ERA PLANETARIA}

La comprensión de los eco-etho-diseños emerge de la comprensión de las geo-graficidades, es decir, de las escrituras, de las grafías, de las poéticas, de los diseños - dibujados por en y desde la tierra misma. Ella es el Ethos. Ella se escribe e inscribe en sus pieles profundas en tanto sensibles; ella se dibuja y pinta, se compone y suena; se piensa y piensa. La distancia de todo lo global: las comunicaciones, los modos de ser y de sentir, de vivir y de amar, de hacer política y de politizar; la distancia de todo aquello que haya emergido de la razón universal, ahora llamada global, es el punto de partida de un pensamiento emergente de la diversidad, la singularidad y la diferencia.

Lo global es lo unificado en el mundo del cálculo. Lo planetario es la singularidad-diversidad de mundos de vida. Cada lugar del planeta es distinto, diverso; cada lugar es metamorfosis permanente, flujo, cambio, transformación. Cada espacio del globo busca ser idéntico y universal. Por ello, diseñar atendiendo al diseño del oikos, de la casa, del ethos; comprender sus grafías, interpretar sus devenires, es poder escuchar las voces de la tierra, sus gritos, sus susurros y sus silencios. 
ANA PATRICIA NOGUERA, DIANA ALEXANDRA BERNAL Y SERGIO ECHEVERRI VOCES Y SILENCIOS DE LA TIERRA EN LA COMPOSICIÓN POLIFÓNICA DE LAS GEOGRAFÍAS ÉTICO-POÉTICAS SUR-SUR

El Diseño de transición, que despliega bellamente y bio-gráficamente el pensador ambiental colombiano Arturo Escobar en su reciente obra $A u$ tonomía y Diseño. La realización de lo comunal (2017), nos ha motivado a pensar el ethos ambiental sur, como un geo-diseño que debe comprenderse éticamente, por cuanto los diseños de la Tierra son los diseños de la casa que habitamos y nos habita en tanto tierra que somos. Así, intentamos pensar-dibujar la Paz que tanto anhelamos no solo en Colombia, sino en los diversos mundos que coexisten en el planeta. La Paz ha sido el centro de las tensiones políticas hoy, en Colombia, luego de una guerra entre las FARC (Fuerzas Armadas Revolucionarias de Colombia), el ejército nacional y los Paramilitares. Sin embargo, el pensamiento predominante sobre qué es la Paz, sigue siendo un concepto de Paz metafísica, biopolíticamente elaborado, para que la Tierra-que somos- ese ethos de todos los ethos, esa casa de todas las casas, no se introduzca en las conversaciones y decisiones para implementar y construir Paz, como lugar, comunidad ecológica, entramado fundacional de toda vida, víctima de toda guerra y por supuesto, "plétora de recursos" por los cuales, y de manera a veces oculta, se han dado las guerras en Colombia.

En el diseño de la Paz, hay una ausencia imperdonable: la Tierra. Si se habla de ella, se habla en términos de propiedad, fuente de recursos, base de la economía y de los capitales, pero no se toma en cuenta como víctima y testigo de las más infames atrocidades, ni se piensa que para construir la Paz entre los humanos es necesario construir la Paz con la Tierra.

La Tierra pensada geopolíticamente ha sido el centro, el objetivo más importante de las guerras en Colombia, porque la voracidad de los capitales está legalizada en el discurso oficial de la guerra y, tristemente, de la Paz. La responsabilidad ética-ambiental adquiere en estos tiempos de penuria una importancia trascendental. Diseñar la Paz implica comprender los diseños de la Tierra a lo largo ancho y profundo de los geo-tiempos, por fuera de la geología como disciplina moderna puesta al servicio del extractivismo minero, de la biología como disciplina moderna puesta al servicio de la explotación, manipulación y control de la vida para fines industriales, es decir del control biopolítico de la naturaleza, no la de Humboldt (Wulf, 2017), sino la mecanicista que aún pervive en muchas escuelas donde se imparte la enseñanza de esta ciencia.

Los geodiseños muestran las ontologías relacionales de todo ser. La Tierra es una plétora rizomática (Deleuze-Guatarri, 2010) de seres entretejidos, enraizados, en florecimiento, en relaciones entrópicas, autopoiésicas y 
ANA PATRICIA NOGUERA, DIANA ALEXANDRA BERNAL Y SERGIO ECHEVERRI VOCES Y SILENCIOS DE LA TIERRA EN LA COMPOSICIÓN POLIFÓNICA DE LAS GEOGRAFÍAS ÉTICO-POÉTICAS SUR-SUR

auto-organizativas cuyas conexiones son emergencias enigmáticas y aún inexplicables -afortunadamente-, de la vida misma. Así, el diseño de transición se compromete con la radical transformación de los diseños geopolíticos y mecanicistas que culturalmente hemos construido dentro de la industrialización de la tierra. El tránsito de diseños eficientes del pensar, conocer, habitar y construir en la industrialización de la tierra, a diseños en clave del ethosTierra, implica una salida del sujeto diseñador sobre el objeto diseñado, a una exterioridad habitada donde una intemperie: sin piso ni techo, sin puertas ni ventanas teóricas ni metodológicas ofrecidas por las ciencias del diseño, una intemperie como exterioridad habitada (Grosso, 2015) acoge a todos y a todo en una red amorosa de alteridades radicales. El diseño de transición emerge de la vida, diseñadora de todo. Nada está por fuera de ese diseño fundacional de todo ser. Y ¿cómo es dicho diseño? ¿Qué ontologías relacionales lo configuran? La Creación como acontecimiento del todo darse, emerge de la potencia (virtus) del ser. No hay modelos, ni fórmulas. Ella es sagrada, como sagrado es todo lugar donde acontece lo epifánico: el encuentro de los dioses y los hombres, de lo divino y lo mortal, del cielo y la tierra, dirá Heidegger (Heidegger, 1973). Así, el origen de la obra de Arte está en la experiencia estética, extática del ethos, es decir, del Ser estando. Una disolución del ethos en lo sensible y lo sensible como ethos, permite comprender cómo el diseño de artefactos y de maneras de habitar, para construir alternativas culturales, maneras-otras de habitar la Tierra, no emerge de una condición teórica, característica del conocimiento moderno, sino del sentir, de lo sensible, como contacto entre las pieles de la Tierra. La descentración de la sensibilidad será la apertura a un diseño geo-hermenéutico que comprenda las creaciones de Gaia y así continúe permitiendo que Gaia florezca. Sin esto, no será posible una Paz duradera y profunda, integral y compleja. Con seguridad, la Paz de los cementerios emergerá de la guerra contra la Tierra, que es la promesa de Paz que se está construyendo tristemente, en Colombia.

\section{REFERENCIAS BIBLIOGRÁFICAS Y AUDIOVISUALES}

Alvarado, Sara Victoria; Pineda, Jaime; Correa Tello, Karen (eds.) (2017). Polifonías del Sur. Desplazamientos y desafíos de las Ciencias Sociales. CLAcso Manizales: Universidad de Manizales, Centro de estudios avanzados en niñez y juventud. Bogotá: CINDE - Fundación Centro Internacional de Educación y Desarrollo Humano. 
ANA PATRICIA NOGUERA, DIANA ALEXANDRA BERNAL Y SERGIO ECHEVERRI VOCES Y SILENCIOS DE LA TIERRA EN LA COMPOSICIÓN POLIFÓNICA DE LAS GEOGRAFÍAS ÉTICO-POÉTICAS SUR-SUR

Alvarado, Sara Victoria; Pineda, Jaime; Correa Tello, Karen (2017). Polifonías de la Re-existencia. Otras voces del Pensamiento Crítico. En: Alvarado, Sara Victoria; Pineda, Jaime; Correa Tello, Karen (eds.) (2017) Polifonías del Sur. Desplazamientos y desafíos de las Ciencias Sociales. Clacso - Manizales: Universidad de Manizales, Centro de estudios avanzados en niñez y juventud. Bogotá: CINDE - Fundación Centro Internacional de Educación y Desarrollo Humano. Páginas 30 a 112.

Ángel-Maya, Augusto (1996). El reto de la vida. Ecosistema y Cultura. Una Introducción al estudio del medio ambiente. Bogotá: Ecofondo.

Ángel-MayA, Augusto (2000). La aventura de los símbolos. Una visión ambiental de la historia del pensamiento. Bogotá: Ecofondo.

Ángel-Maya, Augusto (2000a). Ética, sociedad y medio ambiente. En Revista Gestión y Ambiente. Medellín: Universidad Nacional de Colombia, Sede, n. ${ }^{\circ}$, diciembre 2000, páginas 9-16.

Ángel-Maya, Augusto (2001). El retorno de Icaro. Cali: Corporación Universitaria Autónoma de Occidente cuaO.

Ángel-Maya, Augusto (2001a). Platón o la pirámide invertida. Tomo II, La Razón de la Vida. Medellín: IDEA Universidad nacional de Colombia, Sede.

Ángel-Maya, Augusto (2001b). El concepto de naturaleza en Aristóteles. Tomo III La Razón de la Vida. Medellín: IDea Universidad Nacional de Colombia, Sede.

Ángel-Maya, Augusto (2001c). La razón de la Vida, tomo 1, dedicado a los Presocráticos: una perspectiva en la construcción de una ética ambiental, Manizales: IDEA Universidad Nacional de Colombia, Sede.

Ángel-Maya, Augusto (2001d). La razón de la Vida, tomo 4, dedicado a la Filosofía Moderna: Spinoza, Kant, Hegel, Marx y Nietzche: una perspectiva en la construcción de una ética ambiental, Manizales: IDEA Universidad Nacional de Colombia, Sede.

Ángel-Maya, Augusto (2002). El Retorno de Ícaro. La razón de la vida. Muerte y vida de la filosofía. Una propuesta ambiental. Bogotá: ASOCARs, IDEA, PNUMA-PAL, PNUD.

Boff, Leonardo (2001). Etica planetaria desde el Gran Sur. Madrid: Editorial Trotta.

CAPra, Fritjof (1998). La Trama de la Vida. Una nueva perspectiva de los Sistemas Vivos. Barcelona: Anagrama.

Coccia, Emanuele (2011). La vida sensible. Buenos Aires: Marea, Vox Populi.

Comisión Mundial del Medio Ambiente y del Desarrollo (1992). Nuestro futuro común. Madrid: Alianza Editorial.

Chacón, C.A. (2012). Pensamiento ambiental del maestro: Ethos-Cuerpo en clave de Bio-Geo-Poéticas del Habitar. En: Revista de Investigación de la Universidad del Quindío, No. 22, pp 22-29.

Deleuze, Gilles; GuatTari, Félix (1993). ¿Qué es la Filosofía?. Barcelona: Anagrama.

Deleuze, Gilles; Guattari, Félix (2010). Mil Mesetas. Capitalismo y esquizofrenia. Valencia: PRE-TEXTOS.

Echavarria, Juan Manuel (2009). La Guerra que no hemos visto. Un proyecto de Memoria Histórica. Bogotá: Fundación Puntos de Encuentro. 
ANA PATRICIA NOGUERA, DIANA ALEXANDRA BERNAL Y SERGIO ECHEVERRI VOCES Y SILENCIOS DE LA TIERRA EN LA COMPOSICIÓN POLIFÓNICA DE LAS GEOGRAFÍAS ÉTICO-POÉTICAS SUR-SUR

Echavarria, Juan Manuel (2013). Requiem NN. Documental. Producción: Lulo Films y Fundación Puntos de Encuentro. Estreno en el Museo de Arte Moderno MOMA, de Nueva York.

Escobar, Arturo (2014). Sentipensar con la Tierra. Nuevas lecturas sobre Desarrollo, Territorio y Diferencia. Medellín: Ediciones unaula, Pensamiento Vivo.

Escobar, Arturo (2017). Autonomía y Diseño. La realización de lo comunal. Buenos Aires: Tinta Limón.

Grosso, José Luis (2015). IV Cátedra Internacional sobre Pensamiento Ambiental: "El Extar cuerpos. Cuerpos-entre-cuerpos. Exterioridad Habitada y Alteridad Radical" Manizales: Universidad Nacional - Grupo de Pensamiento Ambiental.

Heidegger, Martin (1973). El origen de la Obra de arte. En: Heidegger, Martin. Arte y Poesía. México: Breviarios del Fondo de Cultura Económica.

Heidegger, Martin (2005). ¿Qué significa pensar? Madrid: Editorial Trotta.

Heidegger, Martin (2006). Hölderlin y la Esencia de la Poesía. En: Heidegger, Martin. Arte y Poesía. México: Breviarios del Fondo de Cultura Económica.

Heidegger, Martin (2012). Ser e tempo. Tradução, organização, nota prévia, anexos e notas: Fausto Castilho. Campinas, S.P: Editora da Unicamp; Petrópolis, RJ: Editora Vozes.

Heidegger, Martin (2012a). Construir, habitar, pensar. In: Heidegger, Martin. Ensaios e conferencias. Tradução de Emmanuel Carneiro, Leão Gilvan Foge e Marcia Sá Cavalcante Schuback. 8 ed. Petrópolis: Editora Vozes; Bragança Paulista: Editora Universitária São Francisco.

Hölderlin, Friedrich (2007). Hiperión o El eremita en Grecia. Madrid: Ediciones Hiperion.

HöLDERLIN, Friedrich (2014). Poemas. Barcelona: Icaria.

Husserl, Edmund (1959). Fenomenología de la Conciencia del Tiempo Inmanente. Buenos Aires: Editorial Nova.

Husserl, Edmund (1962). La Filosofía en la Crisis de la Humanidad Europea in Filosofía como ciencia estricta. Buenos Aires: Editorial Nova.

Husserl, Edmund (1982). Idées Directrices pour une Phénoménologie et une Philosophie Phénoménologique Pure. Livre second: Recherches Phénoménologiques pour la Constitution. Paris: Press Universitaires de France.

HusSerL, Edmund (1991). La crisis de las ciencias europeas y la fenomenología trascendental. Barcelona: Crítica.

Kant, Inmanuel (1972). Crítica de la razón práctica. Porrúa, México.

Kusch, Rodolfo (1976). Geocultura del Hombre Americano. Buenos Aires: Fernando García Cambeiro. Estudios Latinoamericanos.

Leff, Enrique (2001). Ecología y Capital. Racionalidad Ambiental, Democracia Participativa y Desarrollo Sustentable. 4. ${ }^{a}$ edición. México: Siglo xxi Editores UNAM: Instituto de Investigaciones Sociales.

Mesa, Carlos (2010). Superficies de Contacto. Adentro, en el espacio. Medellín: Mesa Editores. 
ANA PATRICIA NOGUERA, DIANA ALEXANDRA BERNAL Y SERGIO ECHEVERRI VOCES Y SILENCIOS DE LA TIERRA EN LA COMPOSICIÓN POLIFÓNICA DE LAS GEOGRAFÍAS ÉTICO-POÉTICAS SUR-SUR

MuÑoz, Germán (2015). Juvenicidio en Colombia: crímenes de Estado y prácticas socialmente aceptables. En: Valenzuela, José Manuel, Coord. Juvenicidio. Ayotzinapa y las vidas precarias en América Latina y España. Barcelona: Ned Ediciones; Guadalajara: ITESo; Tijuana: El Colegio de la Frontera Norte.

Nancy, Jean Luc (2003). Corpus. Madrid: Ed. Arena Libros.

Nietzsche, Friedrich (2000). Obras Inmortales. Tomo 4: De los Fragmentos Póstumos: El sujeto como ficción lógica y regulativa. Barcelona: Edicomunicación, S.A.

Noguera, Ana Patricia (2004). El Reencantamiento del Mundo. Bogotá - México: Universidad nacional Sede Manizales - PUMA Serie PAL.

Noguera, Ana Patricia (2012). Cuerpo-Tierra: El Enigma, El Habitar, La Vida. Emergencias de un Pensamiento Ambiental en clave del Reencantamiento del Mundo. Berlín: EAE.

Noguera, Ana Patricia (2016). Paisajes del desarrollo: evocación, rememoración, conmemoración y reencantamiento. En: Noguera, Patricia et all. Voces del Pensamiento Ambiental: Tensiones entre Desarrollo y Abya Yala. Bogotá: Editorial Universidad Nacional de Colombia.

Noguera, Ana Patricia y Echeverri, Sergio (2019). Ethos-Cuerpo-Tierra. Diseñosotros en tiempos de transición civilizatoria. En: Noguera, Ana Patricia, editora académica (2019) ¿Estamos habitando poéticamente nuestras geografías-sur? Polifonías éticas-estéticas emergentes del Pensamiento Ambiental Latinoamericano. Bogotá: Editorial Universidad Nacional de Colombia. En proceso de Edición.

Noguera, Ana Patricia (2019). Método-esthesis. Lo sensible, el sentir, lo sentido y lo sintiente. Ethos - Cuerpo - Tierra como tejido de caminos del Pensamiento Ambiental Sur. Manizales: Universidad Nacional de Colombia. Inédito.

PARdo, José Luis (1991). Sobre los espacios pintar escribir pensar. Barcelona: Serbal. PinedA, Jaime (2016). Paisajes del desarrollo: desilusión, disolución, devastación y desolación. En: Noguera, Patricia et all. Voces del Pensamiento Ambiental. Tensiones entre Desarrollo y Abya Yala. Bogotá: Editorial Universidad Nacional de Colombia.

Pineda, Jaime y Noguera, Ana Patricia (2017). Rostros del Pensamiento Ambiental. Hacia una geopoética de la reconciliación. En: Alvarado, Sara Victoria; Pineda, Jaime; Correa Tello, Karen (Editores) (2017) Polifonías del Sur. Desplazamientos y desafíos de las Ciencias Sociales. Clacso - Manizales: Universidad de Manizales, Centro de estudios avanzados en niñez y juventud. Bogotá: CINDE - Fundación Centro Internacional de Educación y Desarrollo Humano. Páginas 348 a 385.

SERrEs, Michel (1991). El contrato natural. Valencia: PRE-TEXTOS.

Tuan, Yi Fu. (2013). A cidade e sua distância da natureza. Revista Geograficidade, v. 3, n.3, p. 4-13.

Wulf, Andrea (2017). La Invención de la Naturaleza. El nuevo mundo de Alexander Von Humboldt. Bogotá: Taurus - Penguin Random House Grupo Editorial. YáñEz, Carlos (2010). Viaje al "uno en la multiplicidad". La identidad personal y sus “sí mismos”. Bogotá: Editorial Universidad Nacional de Colombia. 